\title{
Some Aspects of High Manganese Twinning-Induced Plasticity (TWIP) Steel, A Review
}

\author{
Liqing $\mathrm{CHEN}^{\dagger}$, Yang ZHAO and Xiaomei QIN \\ State Key Laboratory of Rolling and Automation, Northeastern University, Shenyang 110819, China \\ [Manuscript received 20 September 2012] \\ (C) The Chinese Society for Metals and Springer-Verlag Berlin Heidelberg
}

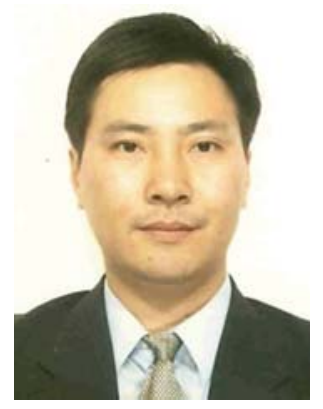

Liqing Chen is a professor in materials science at the State Key Laboratory of Rolling and Automation (RAL), Northeastern University (NEU) of China. He received his $B$. S. degree in Materials Science and Engineering from Northeast University of Technology in 1988 and was awarded Ph.D. degree in Materials Science at Northeastern University in 1995. During 1995-2004, he had been working as a research associate and an associate research fellow at the Institute of Metal Research (IMR), Chinese Academy of Sciences (CAS). His research interests include forming process, microstructures and mechanical properties of advanced metallic materials, processing technologies and mechanical property characterization of special steels and alloys, microalloying and microstructural evolution of the ferrous materials, and light metal-matrix composites. Dr. Chen has authored and co-authored more than 100 peer-reviewed papers. He is now the member of the editorial committees of Acta Metallurgica Sinica, Acta Metallurgica Sinica (English Letters), Journal of Materials Science \& Technology, Advances in Materials Research-An International Journal, and Acta Materiae Compositae Sinica.

High manganese twinning-induced plasticity (TWIP) steel is a new kind of structural material and possesses both high strength and superior plasticity and can meet the weight-lightening requirement for manufacturing vehicle body. The excellent formability of the TWIP steel comes from the extraordinary strain hardening effect during plastic deformation. The reduction of specific weight by aluminum alloying and strain hardening effect can lead to an effective weight reduction of the steel components, and provide a better choice for materials in vehicle body design. The TWIP effect in high Mn steels is generally associated with the successive workhardening generated by twins and influenced by some factors, such as $\mathrm{Mn}$ content, Al addition revealed by stacking fault energy (SFE), grain size, deformation temperature and strain rate. The present review introduces some aspects of the TWIP steels relating to their physical metallurgy, influencing factors associated with their deformation mechanisms, and a prospect for the future investigation is also described. Moreover, as a potential candidate for replacing $\mathrm{Ni}-\mathrm{Cr}$ austenitic stainless steel, researches on the oxidation behavior and corrosion resistance of Fe-Mn-Al-C system steels are also reviewed.

KEY WORDS: Twinning-induced plasticity (TWIP) steel; Physical metallurgy; Stacking fault energy; Mechanical properties; Oxidation behavior; Corrosion resistance

\section{Introduction}

The transformation-induced plasticity (TRIP) and twinning-induced plasticity (TWIP) aided steels

† Corresponding author. Prof., Ph.D.; Tel.: +86 24 83681819; Fax: +86 24 23906472; E-mail address: lqchen@mail.neu. edu.cn (Liqing CHEN)

DOI10.1007/s40195-012-0501-x are the two representatives to have received great attention as the auto body materials. The prototype of TWIP steels comes from the high manganese austenitic steel, which was firstly discovered by Sir Robert Hadfield in $1888^{[1]}$. The earlier work on high manganese ferrous alloys, e.g. by Schuman ${ }^{[2]}$, Remy and Pineau ${ }^{[3]}$ and Kim et al. ${ }^{[4]}$, did not receive much attention originally. About one decade ago, the work of Frommeyer and Grässel et al. ${ }^{[5-7]}$, and the need for 
advanced high strength steels (AHSS) aroused the interest of the mechanical properties of high manganese TWIP steels. Only recently the TWIP steels have received considerable attention owing to the increasing demand for high-performance auto materials from automobile manufacturing industry. Currently, high manganese TWIP steels become one of the most attractive and potential materials for manufacturing vehicle components due to their excellent combination of strength and elongation.

The strength and elongation of metallic materials have long been considered as conflict and the research efforts for obtaining materials with both high strength and toughness have been in progress. High Mn austenitic steels possess the highest product of strength and ductility, normally $4 \times 10^{4}-6 \times$ $10^{4} \mathrm{MPa} . \%$ or more, as depicted in Fig. 1 where the relationship between tensile strength and elongation is summarized for typical ferrous and nonferrous materials utilized in automobile components. The dominant deformation mode in TWIP steel is dislocation glide, and the deformation-induced twins gradually reduce the effective glide distance of dislocations which results in the "dynamical Hall-Petch effect". The extra-high product of strength and ductility of these steels is now recognized to be from the high rate of strain hardening associated with the deformation twinning phenomenon, which allows for the required combination of higher strengths and higher uniform elongations. Some TRIP steels have already been commercialized ${ }^{[8]}$, and a few years ago hot coils of a TWIP steel were successfully fabricated in the commercial production line of POSCO Kwangyang Mill [9]. It can be said that the TWIP steels have reached the stage of large scale industrial testing.

Till now, three main types of high manganese TWIP steel, Fe-Mn-C, Fe-Mn-C-Al and Fe-Mn-Si$\mathrm{Al}$, have been extensively investigated. Among these TWIP steels, the more interesting is that $\mathrm{Al}$ addition to the TWIP steel could lead to an effective reduction of the specific weight of these steels $\left(6.8-7.3 \mathrm{~g} / \mathrm{cm}^{3}\right.$, depending on $\mathrm{Al}$ content), which is particularly significant to the automobile industry and makes less carbon emission and fuel consumption possible. Thus, the industrial focus is now mainly on TWIP steels of Fe-Mn-C-Al and Fe-Mn-Si-Al alloy systems.

Considering their potential as the advanced auto

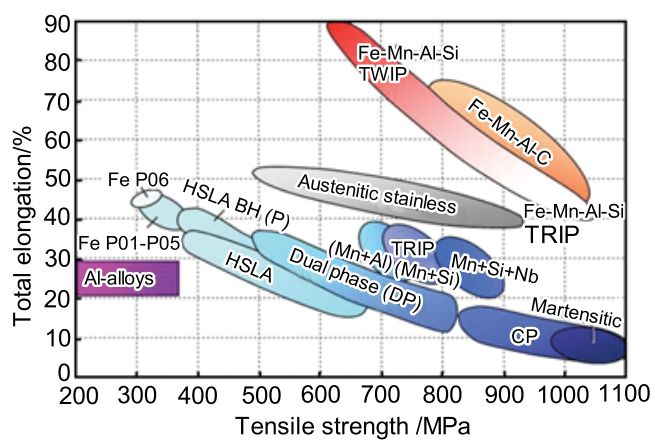

Fig. 1 Relationship between the yield strength and elongation in various automobile steels body material, it is necessary to review the factors that influence the mechanical properties of the high manganese Fe-Mn-Al-C and Fe-Mn-Si-Al steel classes. In this review, the alloying fundamentals of TWIP steel is briefly introduced at first, while the emphasis of this presentation is put on the effects of the grain size, strain rate and deformation temperature on the tensile properties of the Fe-Mn-Al-C and Fe-Mn-Si$\mathrm{Al}$ alloy systems in associating with their deformation mechanisms. As a class of age-hardenable austenitebased steels containing the high content of $\mathrm{Mn}, \mathrm{Al}$ and $\mathrm{C}$, this Fe-Mn-Al-C steel class was first developed in late 1950s for the use of cryogenic or highly corrosive environments by replacing the high $\mathrm{Ni}-\mathrm{Cr}$ steel ${ }^{[10-12]}$ and recently reappraised as the promising candidate for austenitic stainless steel by adding some content of $\mathrm{Cr}^{[13,14]}$. Thus, the evaluation of the high temperature anti-oxidation behavior and corrosion resistance of Fe-Mn-Al-C system steels is also presented.

\section{Alloying and Microstructures of TWIP Steels}

High manganese steels are composed of single austenite phase or multi phase with high content of austenite phase and can be alloyed with a large amount of alloying elements. Generally, in order to obtain the fully austenitic microstructure, sufficient content of $\mathrm{Mn}$ is required to add to the TWIP steels. Some other elements, e.g. C, Si and/or Al, are also needed in order to obtain the high strength and the large uniform elongation associated with straininduced twinning. For some special purposes, e.g. to improve the oxidation and corrosion resistance, $\mathrm{Cr}$ is a usual element to be used in TWIP steels along with $\mathrm{Al}^{[13-17]}$.

Depending on the alloy system, the carbon content in TWIP steels is either low $(<0.05 \mathrm{wt} . \%)$ or high $(\sim 1.0 \mathrm{wt} . \%)$, typically in the range of $0.5-1.0 \mathrm{wt} . \%{ }^{[18]}$. Manganese stabilizes austenite, however, if its content is less than 15 wt. $\%, \alpha^{\prime}$-martensite is formed, which aggravates the formability. If the content of $\mathrm{Mn}$ exceeds $30-32$ wt. $\%$, there will be a brittle phase $\beta-\mathrm{Mn}$ to form in the microstructure ${ }^{[11]}$. Thus, the Mn content is normally in the range of $15-30 \mathrm{wt} . \%$. Si and $\mathrm{Al}$ may be added to achieve a stable and fully austenitic microstructure with low stacking fault energy (SFE) in the range of $15-30 \mathrm{~mJ} / \mathrm{m}^{2[18]}$. Effect of alloying element on properties of high manganese steels is shown in Table 1.

It is well known that carbon can improve the stability of austenite and strengthen the steels. Also, it inhibits the formation of $\varepsilon$-martensite by increasing the SFE. The $\gamma \rightarrow \varepsilon$ transformation temperatures decrease with increasing Mn content. Silicon improves strength by solid solution strengthening. Si addition is effective for refining $\varepsilon$-martensite plates and increasing fracture strength, although it does not improve ductility. The high $\mathrm{Al}$ content in high $\mathrm{Mn}$ steels increases the SFE of austenite ${ }^{[19]}$. The formation of 
Table 1 Effect of alloying elements on properties of high manganese steels

\begin{tabular}{cccccccc}
\hline Effect & $\mathrm{C}$ & $\mathrm{Mn}$ & $\mathrm{Si}$ & $\mathrm{B}$ & $\mathrm{Ti}$ & $\mathrm{N}$ & $\mathrm{Al}$ \\
\hline$\gamma$-stabiliser & $\sqrt{ }$ & $\sqrt{ }$ & & & & $\sqrt{ }$ & $\sqrt{ }$ \\
Solid solution strengthening austenite & $\sqrt{ }$ & & $\sqrt{ }$ & & & $\sqrt{ }$ & $\sqrt{ }$ \\
$\varepsilon$-matrensite refinement & & & $\sqrt{ }$ & & & & $\sqrt{ }$ \\
Hot ductility & & & & $\sqrt{ }$ & $\sqrt{ }$ & & \\
\hline
\end{tabular}

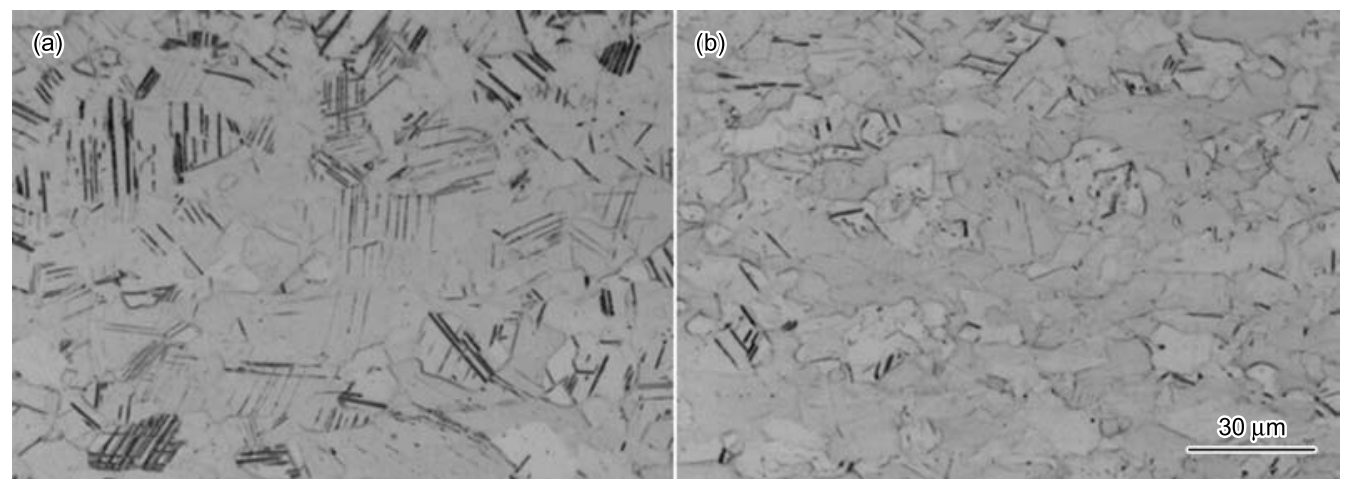

Fig. 2 Optical images showing the microstructures of Fe-23Mn-2Al-0.2C steel hot rolled and followed by air cooling (a) and water quenching $(\mathrm{b})^{[22]}$

$\varepsilon$-martensite is suppressed by $\mathrm{Al}$ addition and an $\mathrm{Al}$ addition is also very effective for improving lowtemperature toughness. However, Al can segregate on the grain boundaries during solidification, and produce a low melting point intermetallic compound such as $\mathrm{Fe}_{2} \mathrm{Al}_{5}$ having a melting point about $1170{ }^{\circ} \mathrm{C}$ on the grain boundaries, which lead to a weakness in the casting structure. So, the Al content should be controlled in a lower level.

Adding small amounts of $\mathrm{B}, \mathrm{Ti}$ and $\mathrm{Zr}$ into the high $\mathrm{Mn}$ steels alloyed with $\mathrm{Al}$ can improve the hot ductility of the steels. Nitrogen is an effective strengthening element in austenite, e.g. adding nitrogen to the Fe-16.5Mn alloy decrease the martensite start temperature and also reduces the volume fraction of $\varepsilon$-martensite.

In Fe-Mn equilibrium phase diagram, the Fe-rich side has an open $\gamma$ loop and in the range of $5_{-}^{-}$ 25 wt.\%Mn the microstructures of Fe-Mn alloys is dominated by the presence of $\alpha^{\prime}$-martensite at a low $\mathrm{Mn}$ content and $\varepsilon$-martensite at a higher $\mathrm{Mn}$ content ${ }^{[20]}$. Approximately $27 \mathrm{wt} . \% \mathrm{Mn}$ is required to obtain metastable austenite at the room temperature. Relatively small $\mathrm{C}$ addition of $\sim 0.6 \mathrm{wt} . \%$ results in martensite free, austenitic microstructures for Mn content as low as 12 wt.\%. The microstructure of TWIP steel is single phase austenitic with coarse grains, which often contain wide recrystallization twins, as revealed by Cooman et al. ${ }^{[20]}$. $\mathrm{Al}$ is added to control the SFE of TWIP steel and also suppresses the formation of the carbide $\mathrm{Fe}_{3} \mathrm{C}$. As mentioned above, the $\mathrm{Al}$ addition, typically less than $3 \mathrm{wt.} \%$, also results in a slight reduction in density which is beneficial to weight reduction of car body. An alternative approach to obtain TWIP steel with a uniform, carbide free, austenitic microstructure is to use a higher Mn content and avoid $\mathrm{C}$ additions. This TWIP steel composition concept typically requires $\mathrm{Si}$ and $\mathrm{Al}$ additions to control the SFE. Jung et al. ${ }^{[21]}$ have shown that small additions of $\mathrm{Al}$ facilitated the TWIP effect and the formation of $\varepsilon$-martensite was effectively suppressed by the addition of $1.5 \mathrm{wt} . \% \mathrm{Al}$ to Fe-15Mn-0.6C TWIP steel. Nitrogen has been found to have similar effects as $\mathrm{Al}$.

The typical microstructures of a TWIP steel Fe$23 \mathrm{Mn}-2 \mathrm{Al}-0.2 \mathrm{C}$ hot rolled at $1150{ }^{\circ} \mathrm{C}$ and followed by air-cooling and water-quenching are presented in Fig. 2(a) and (b), respectively.

In Fig. 2, the more annealing twins can be observed after air cooling than that after water quenching, however, the latter possesses the finer austenitic grains. After tensile deformation to fracture, the annealing twins were disappeared and deformation twins produced, as shown in Fig. 3. The more deformation twins can be found near to the fractured surfaces and irregular-shaped twins exist away from the fractured surfaces.

\section{Mechanical Behaviors of TWIP Steels}

\subsection{Effect of grain size on the mechanical behavior of TWIP steels}

It has long been recognized that the grain size is closely related to the mechanical behavior of materials and the grain refinement is a suitable means of the microstructure control for strengthening a material without changing its chemical composition ${ }^{[23]}$. At present, ultra-fine grained metallic materials with average grain size down to $1 \mu \mathrm{m}$ or even to the 

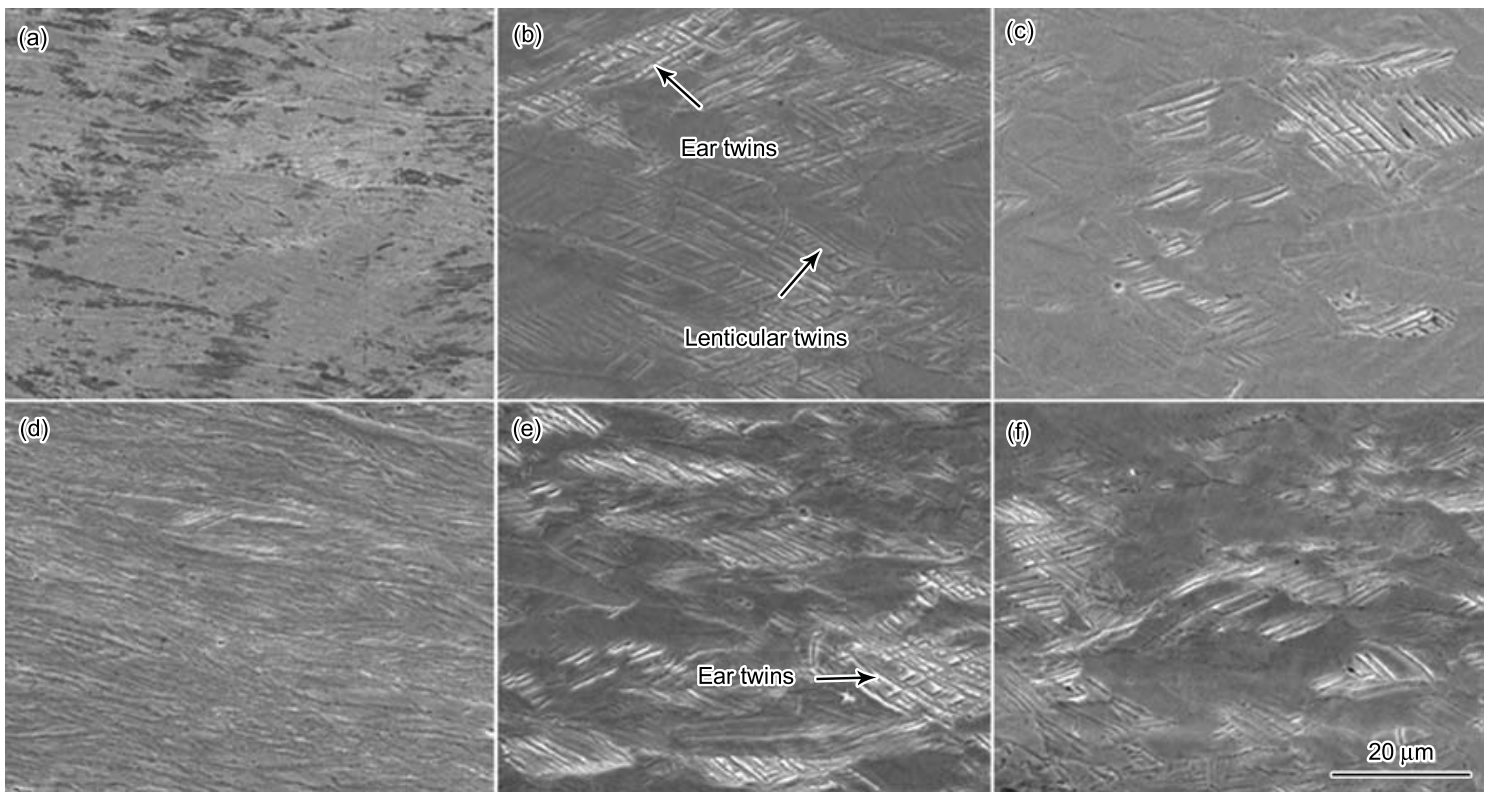

Fig. 3 Optical images showing the microstructures of Fe-23Mn-2Al-0.2C steel tensile deformed to fracture: (a) air cooled and deformed to fracture, near to the fractured surface; (b) air cooled and deformed to fracture, $10 \mathrm{~mm}$ away from the fractured surface; (c) air cooled and deformed to fracture, $20 \mathrm{~mm}$ away from the fractured surface; (d) water cooled and deformed to fracture, near to the fractured surface; (e) water cooled and deformed to fracture, $10 \mathrm{~mm}$ away from the fractured surface; (f) water cooled and deformed to fracture, $20 \mathrm{~mm}$ away from the fractured surface ${ }^{[22]}$

sub-micrometer have become possible by severe plastic deformation techniques ${ }^{[24]}$. For the ferritic steels or pure fcc metals with medium to high SFE, when the grain size approaches $1 \mu \mathrm{m}$, the ductility or uniform elongation in the tensile test is significantly reduced to a few percent ${ }^{[25]}$. In fcc metals and alloys with low SFE such as TWIP steel, however, the information concerning the range of the grain size effect on both strength and ductility is still limited.

From the studies available, it is accepted that the effect of the grain size on the dislocation structure in TWIP steel has important role in the occurrence of the mechanical twin. With decreasing the grain size, the deformation twins are reduced and the ductility is suppressed. In a recent study conducted by Ueji et al. ${ }^{[23]}$, the strengthening effect of the grain size on the mechanical properties of Fe-31Mn-3Al-3Si (wt.\%) TWIP steel was investigated and the results indicated that the mechanical twinning was significantly suppressed by the grain refinement. Fine-grained steel (grain size $d=1.8 \mu \mathrm{m}$ ) show high strength with adequate ductility (Fig. 4), which differs from the case of the alloys with medium to high SFE. This observation suggests that the large ductility lies on not only the twinning but also in the suppressed dynamic recovery due to low SFE. A similar result was lately reported by Wang et al. ${ }^{[26]}$ for a Fe-24.8Mn-3.17Si3.12Al-0.022C TWIP steel. They revealed that the number of deformation twins increases with the increase of the grain size, which lead to greater TWIP effect in the coarse-grained specimen than in the finegrained specimen. This can be attributed to the dependence of the critical stress for formation of deformation twins on the grain size. Table 2 lists the

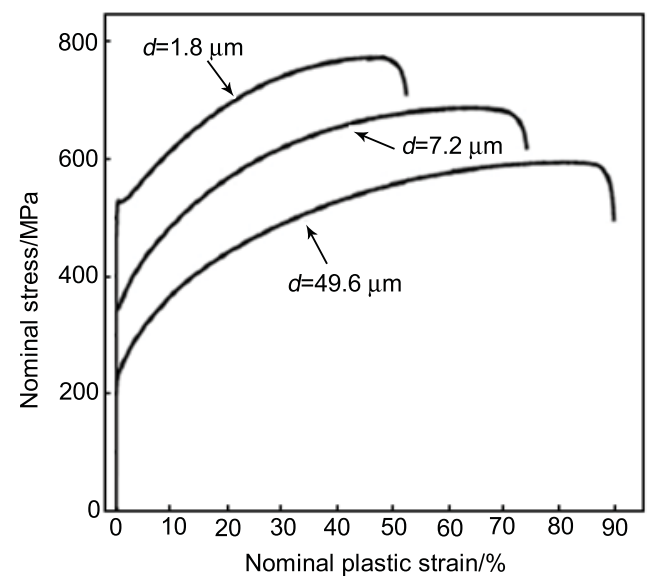

Fig. 4 Nominal stress-strain curves of the Fe-31Mn3Al-3Si (TWIP) steel after $88 \%$ cold rolled and subsequently annealed at $700{ }^{\circ} \mathrm{C}(d=1.8 \mu \mathrm{m})$, $800{ }^{\circ} \mathrm{C}(d=7.2 \mu \mathrm{m})$ or $1000{ }^{\circ} \mathrm{C}(d=49.6 \mu \mathrm{m})$ for $1800 \mathrm{~s}^{[23]}$

mechanical behaviors of this TWIP steel for different grain sizes.

It has been reported elsewhere, fine grain sizes may completely inhibit the formation of twin and martensite in low SFE materials ${ }^{[27-29]}$. Furthermore, other investigations ${ }^{[27,30]}$ suggested that the initiation of the twin requires a critical dislocation density (i.e., the twin formation after a given plastic strain). Before the onset of twinning, slip occurs initially by dislocations gliding. Dini et al. ${ }^{[31]}$ also emphasized the importance of the dislocation structure and the grain size effects on the occurrence of mechanical twins. They obtained various grain sizes $(2.1-72.6 \mu \mathrm{m})$ of TWIP steel Fe-31Mn-3Si-3Al by cold rolling and 
Table 2 Mechanical properties of Fe-24.8Mn-3.17Si-3.12Al-0.022C TWIP steel with different grain sizes (after excluding twin boundary) ${ }^{[26]}$

\begin{tabular}{ccccc}
\hline $\begin{array}{c}\text { Grain size } \\
/ \mu \mathrm{m}\end{array}$ & $\begin{array}{c}\text { YS } \\
/ \mathrm{MPa}\end{array}$ & $\begin{array}{c}\text { UTS } \\
/ \mathrm{MPa}\end{array}$ & $\begin{array}{c}\text { Elongation } \\
/ \%\end{array}$ & $\begin{array}{c}\text { Product of tensile stress } \\
\text { and elongation/MPa.\% }\end{array}$ \\
\hline $7(8)$ & 380 & 785 & 68.0 & 53380 \\
$13(19)$ & 285 & 700 & 72.0 & 50400 \\
$30(47)$ & 265 & 675 & 75.0 & 50625 \\
$63(97)$ & 230 & 610 & 79.0 & 48190 \\
\hline
\end{tabular}

Note: YS-yield strength, UTS-ultimate tensile strength
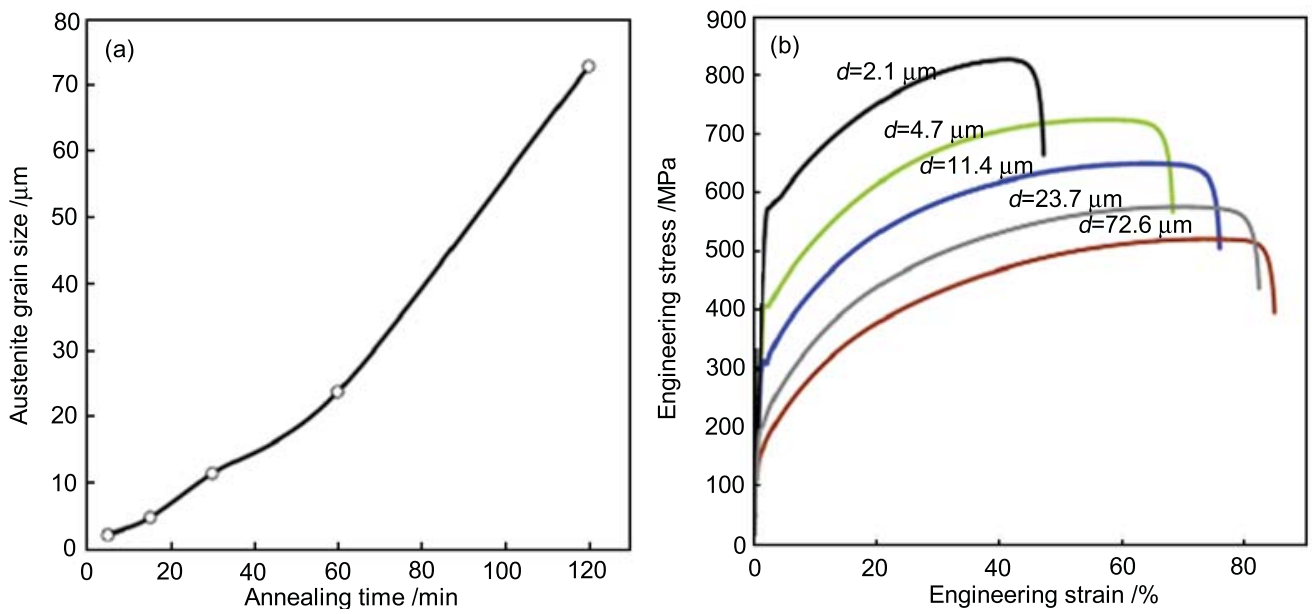

Fig. 5 Variation of the grain size with annealing time (a) and the engineering stress-engineering strain curves (b) for TWIP steel samples with different grain sizes ${ }^{[31]}$

Table 3 The tensile properties of TWIP steel with different grain sizes ${ }^{[31]}$

\begin{tabular}{cccccccc}
\hline $\begin{array}{c}\text { Grain size } \\
/ \mu \mathrm{m}\end{array}$ & $\begin{array}{c}\mathrm{YS} \\
/ \mathrm{MPa}\end{array}$ & $\begin{array}{c}\mathrm{UTS} \\
/ \mathrm{MPa}\end{array}$ & $\begin{array}{c}\mathrm{YS} \\
/ \mathrm{UTS}\end{array}$ & $\begin{array}{c}\mathrm{WH} \\
/ \mathrm{MPa}\end{array}$ & $\begin{array}{c}\text { WHC } \\
/ \mathrm{MPa}\end{array}$ & $\begin{array}{c}\text { Elongation } \\
/ \%\end{array}$ & $\begin{array}{c}\text { Uniform elongation } \\
/ \%\end{array}$ \\
\hline 2.1 & 572.0 & 825.0 & 0.69 & 253.0 & 294.6 & 47.2 & 39.8 \\
4.7 & 404.4 & 723.8 & 0.56 & 319.4 & 349.8 & 68.4 & 56.5 \\
11.4 & 311.9 & 648.1 & 0.48 & 336.2 & 339.8 & 75.9 & 63.1 \\
23.7 & 208.6 & 575.4 & 0.36 & 366.8 & 318.2 & 82.4 & 70.0 \\
72.6 & 123.1 & 519.4 & 0.24 & 396.3 & 295.4 & 85.0 & 76.3 \\
\hline
\end{tabular}

Note: WH-work hardening; WHC-work hardening capacity

annealing at $850{ }^{\circ} \mathrm{C}$ for different times (5-120 min), shown in Fig. 5. For each grain size, the Hollomon analysis and also the Crussard-Jaoul (C-J) analysis as an alternative method to describe the work hardening (WH) behavior were investigated. The results in Table 3 indicated that the optimum mechanical properties as a function of work hardening capacity (WHC) can be obtained by changing the grain size. The microstructural observations showed that the pile-ups of planar dislocations are necessary for triggering the mechanical twinning and grain refinement suppresses the mechanical twinning in TWIP steel. Furthermore, the mechanical twinning increases with increasing applied strain. As a result, a high instantaneous work hardening due to the mechanical twin boundaries enhances the uniform elongation. The contribution from the strain of twinning and hardening due to an increase in the hardness of the twinned regions may be also useful in achieving the high strength-ductility in TWIP steels.
In an other study by Dini et al. ${ }^{[32]}$, they also stressed the effect of the grain size on the martensite formation in a high-manganese TWIP steel Fe$36.06 \mathrm{Mn}-2.62 \mathrm{Al}-3.21 \mathrm{Si}-0.32 \mathrm{C}$. The results indicated that the volume fraction of $\alpha_{\mathrm{bcc}}$-martensite increases with increasing austenite grain size. However, the value of the stacking fault probability $\left(P_{\mathrm{sf}}\right)$ does not show a large variation for the samples with different values of the austenite grain size under waterquenching conditions.

Yoo et al. ${ }^{[8]}$ used Fe-28Mn-9Al-0.8C steel (specific weight is $6.87 \mathrm{~g} / \mathrm{cm}^{3}$, much lighter than ordinary commercial steels) as experimental material to examine the factors affecting the tensile properties of high FeMn-Al-C TWIP steels. As usual, they observed that the strength increases and elongation decreases with decreasing grain size. The strain hardening rate of the fine-grained steel remained unchanged to the medium strain level but that of the coarse-grained steel continuously increased to a high strain level, resulting in 
exceptional ductility, as listed in Table 4. The steel showed exceptionally high elongation with reasonable high strength. The yield strength (YS) and ultimate tensile strength (UTS) increased with decreasing the grain size and the trend was opposite for elongation. The product of UTS and total elongation also decreased with decreasing the grain size in spite of the increase of strength, indicating the elongationdominated tensile characteristics of the steel. However, it should be noticed that the product of UTS and total elongation was in the range of $6.7 \times 10^{4}-$ $8.4 \times 10^{4} \mathrm{MPa} \cdot \%$ in the wide grain size span of $5^{-}$ $40 \mu \mathrm{m}$, still much higher than that of conventional TWIP steels of $4 \times 10^{4}-6 \times 10^{4} \mathrm{MPa} \cdot \%$. Besides, postneck elongation was over $10 \%$ for all grain sizes enough to guarantee the good hole expansion properties required to the auto body material.

The representative engineering stress-strain curves of Fe-28Mn-9Al-0.8C with three different grain sizes are shown in Fig. 6(a). The grain size effected on strain hardening of the Fe-28Mn-9Al-0.8C steel can be seen in the plot of strain hardening rate against true strain superimposed on the true stress-strain curves in Fig. 6(b). The strain hardening rate of the finegrained $(5 \mu \mathrm{m})$ steel remained constant up to a true strain of $\sim 0.3$ and then decreased. By contrast, the strain hardening rate of the coarse-grained $(38 \mu \mathrm{m})$ steel was lower than that of the fine-grained steel at the initial stage of plastic deformation but it increased continuously with increasing strain up to a true strain of $\sim 0.5$, reaching the value close to that of fine-grained steel.

Yoo and Park ${ }^{[33]}$ suggested that continuous increase of the strain hardening rate of high manganese Fe-Mn-Al-C austenitic steel, leading to the exceptionally high elongation of $\sim 100 \%$, is attributed to the formation and intersection of th microbands consisting of geometrically necessary dislocations, i.e. microband-induced plasticity. Microbands in the high manganese Fe-Mn-Al-C austenitic steel are crystallographic in nature and usually run through the grain. Therefore, their length scale has the same order as the grain size ${ }^{[34,35]}$. Accordingly, it is plausible that strain hardening by microband-induced plasticity is saturated early in the fine-grained steel compared to the coarse-grained steel.

\subsection{Effect of deformation temperature on the mechan- ical behavior of TWIP steels}

For TWIP steels, twinning is a predominant plastic deformation mechanism at room temperature due to their lower SFE. Since SFE is closely related to temperature, there will be a major influence of deformation temperature on mechanical properties for the steels with SFE-controlled deformation mechanism. Earlier work on Fe-22Mn-0.6C steel conducted by Allain et al..$^{[36]}$ indicated that deformation mechanism and the microstructure will change with the deformation temperature, and their exact calculation showed that displacive transformation can occur during plasticity depending on the SFE $(\Gamma)$. For $\Gamma<18 \mathrm{~mJ} / \mathrm{m}^{2}$, the $\varepsilon$ martensitic transformation occurs, while for $12 \mathrm{~mJ} / \mathrm{m}^{2}<\Gamma<35 \mathrm{~mJ} / \mathrm{m}^{2}$ mechanical twinning takes place.

The general trend of mechanical behavior with deformation temperature is that the strength and elongation decrease with increasing deformation temperatures. Wang et al. ${ }^{[37]}$ calculated the SFE at different deformation temperatures using Allain's approach

Table 4 Room temperature tensile characteristics of Fe-28Mn-9Al-0.8C with three different grain sizes ${ }^{[8]}$

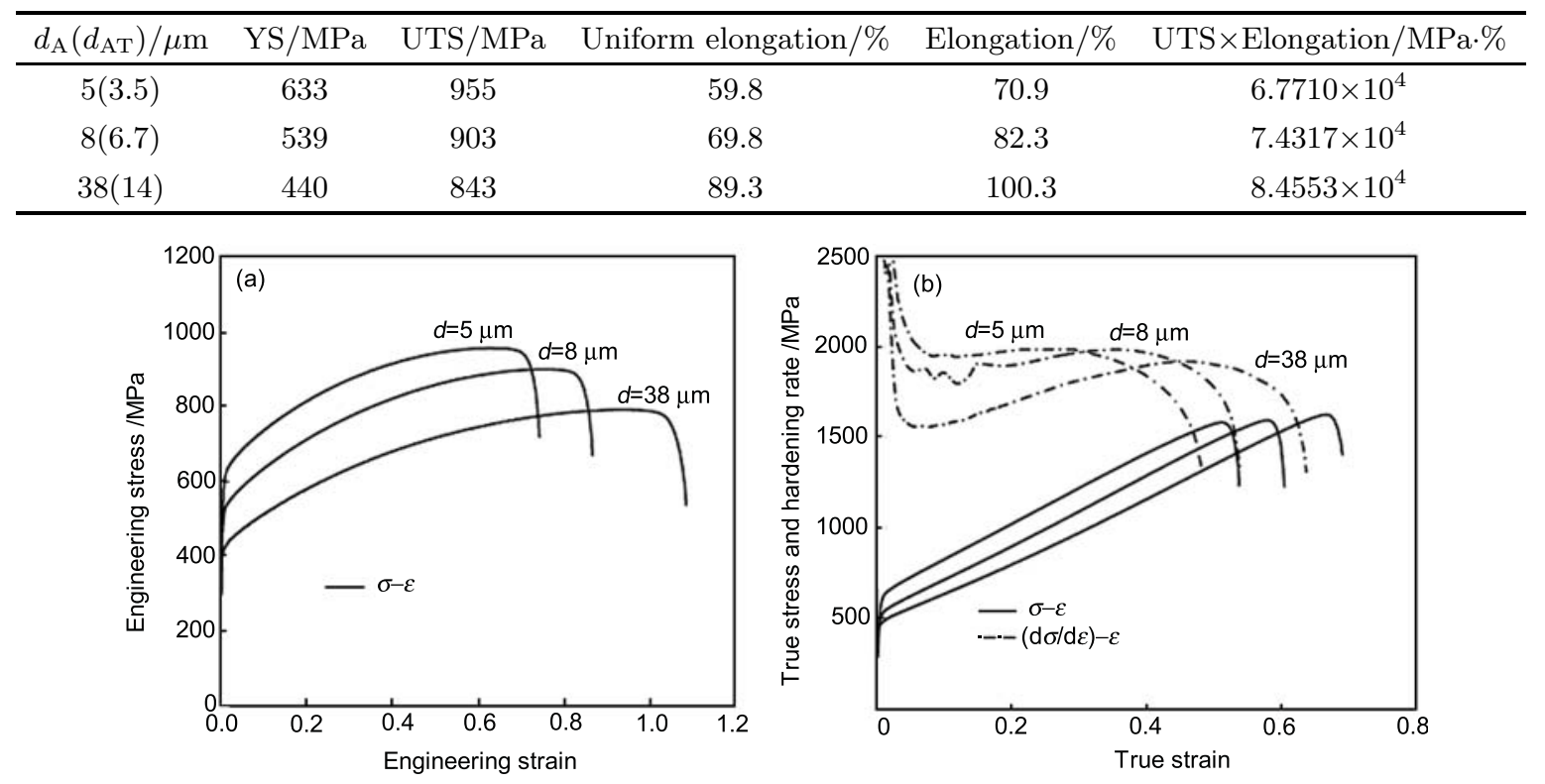

Fig. 6 The representative engineering stress-strain curves of Fe-28Mn-9Al-0.8C with three different grain sizes tested at $25{ }^{\circ} \mathrm{C}$ with the initial strain rate of $10^{-3} \mathrm{~s}^{-1}(\mathrm{a})$, and the true stress-strain curves and the corresponding strain hardening rate as a function of true strain $(b)^{[8]}$ 
and focused on the mechanical properties of Fe-25Mn3Si-3Al TWIP steel and the microstructure evolution with temperature through tensile testing at 25 , 100,200 and $400{ }^{\circ} \mathrm{C}$. The results show that when $21 \mathrm{~mJ} / \mathrm{m}^{2} \leq \Gamma \leq 34 \mathrm{~mJ} / \mathrm{m}^{2}$ in $25{ }^{\circ} \mathrm{C} \leq T \leq 100{ }^{\circ} \mathrm{C}$, the deformation twinning is a main deformation mechanism, while the slipping is a predominant deformation mode when $\Gamma \geq 76 \mathrm{~mJ} / \mathrm{m}^{2}$ in $T \geq 400{ }^{\circ} \mathrm{C}$. The $\mathrm{SFE}$ value was found to decrease with temperature decreasing, and lower SFE would promote deformation twinning and inhibit slip. Deformation twins formed during plastic deformation can act as the obstacles to dislocation movement, resulting in high strain hardening effect such that both high elongation and ultimate tensile strength can be obtained at relatively low temperatures.

For TWIP steels with high $\mathrm{Al}$ and $\mathrm{C}$ contents, however, there is an exceptional situation that elongation will not decrease with increasing the deformation temperature. Yoo et al. ${ }^{[8]}$ measured the engineering stress-strain curves of the coarse-grained Fe$28 \mathrm{Mn}-9 \mathrm{Al}-0.8 \mathrm{C}$ steel tensile-tested with a strain rate of $10^{-3} \mathrm{~s}^{-1}$ at temperatures of $25-400{ }^{\circ} \mathrm{C}$. The results are presented in Fig. 7 and showed that the yield strength at $150-450{ }^{\circ} \mathrm{C}$ was sensitive to the temperature with the value lower than that at $25{ }^{\circ} \mathrm{C}$ while the UTS decreased with increasing temperature. Except $300{ }^{\circ} \mathrm{C}$, total elongation decreased with increasing temperature. Unlike other temperature, serrated flow occurred at $300{ }^{\circ} \mathrm{C}$ with total elongation comparable to that at $25{ }^{\circ} \mathrm{C}$. These characteristics confirm that the serrated flow occurs at $300{ }^{\circ} \mathrm{C}$ is primarily attributed to interaction between dislocationsinterstitial atoms (carbon atoms in this steel) rather than interaction between dislocations-substitutional atoms.

In order to reveal the dependence of deformation mechanism on the temperature in $\mathrm{Fe}-\mathrm{Mn}-\mathrm{Al}-\mathrm{C}$ TWIP steel, Qin et al. ${ }^{[38]}$ performed tensile deformation experiments for Fe-23Mn-2Al-0.2C steel at a wide temperature range from $-60{ }^{\circ} \mathrm{C}$ to $600{ }^{\circ} \mathrm{C}$ (Fig. 8). Microstructural observation and stacking fault energy calculation were carried out for the temperature

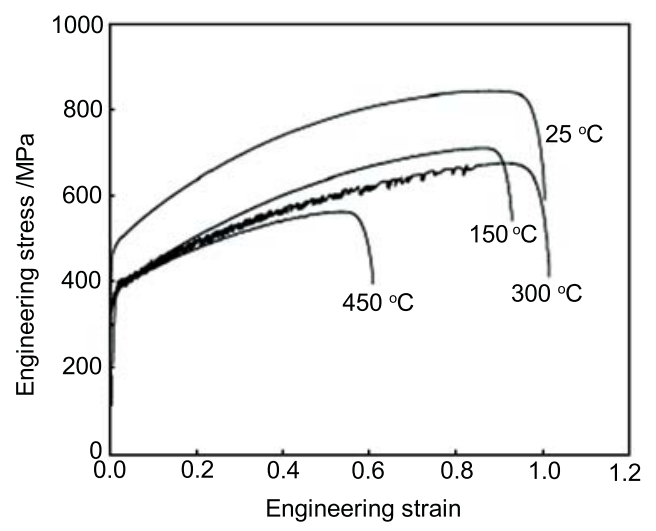

Fig. 7 The representative engineering stress-strain curves of the coarse grained Fe-28Mn-9Al-0.8C tested at various temperatures with the initial strain rate of $10^{-3} \mathrm{~s}^{-1[8]}$ range. The tensile test results in Fig. 9 indicated that with increasing the deformation temperature, the strength and elongation to failure of this steel firstly decrease, then increase and finally decrease. And their peak values appear at $300{ }^{\circ} \mathrm{C}$ during high temperature deformation. As deformation temperature increased from -60 to $600{ }^{\circ} \mathrm{C}$, the stacking fault energy of the steel increases and deformation mechanism is changed from twining to slipping. SEM images in Fig. 10 show that high-density deformation twins appear at lower deformation temperatures, however, they will gradually decrease with increasing temperature. TEM observation as shown in Fig. 11. It reveals that when the sample was deformed at $600{ }^{\circ} \mathrm{C}$, only dislocations and dislocation cells appear in the microstructure. High-density deformation twins formed during low-

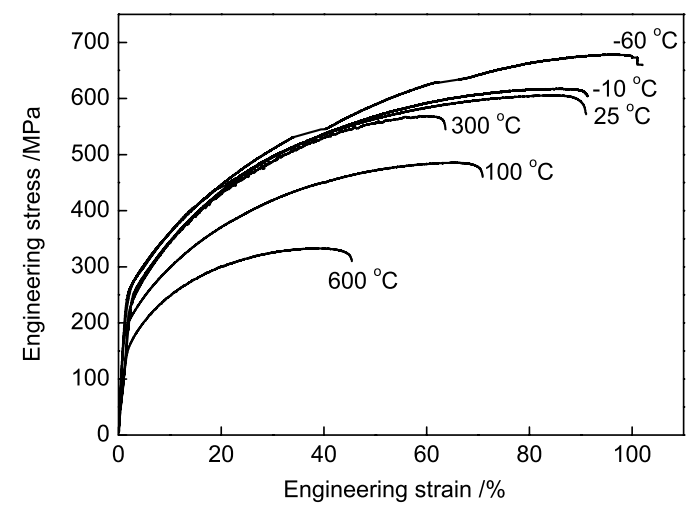

Fig. 8 Engineering stress-strain curves of Fe-23Mn$2 \mathrm{Al}-0.2 \mathrm{C}$ steel at different deformation temperatures $^{[38]}$
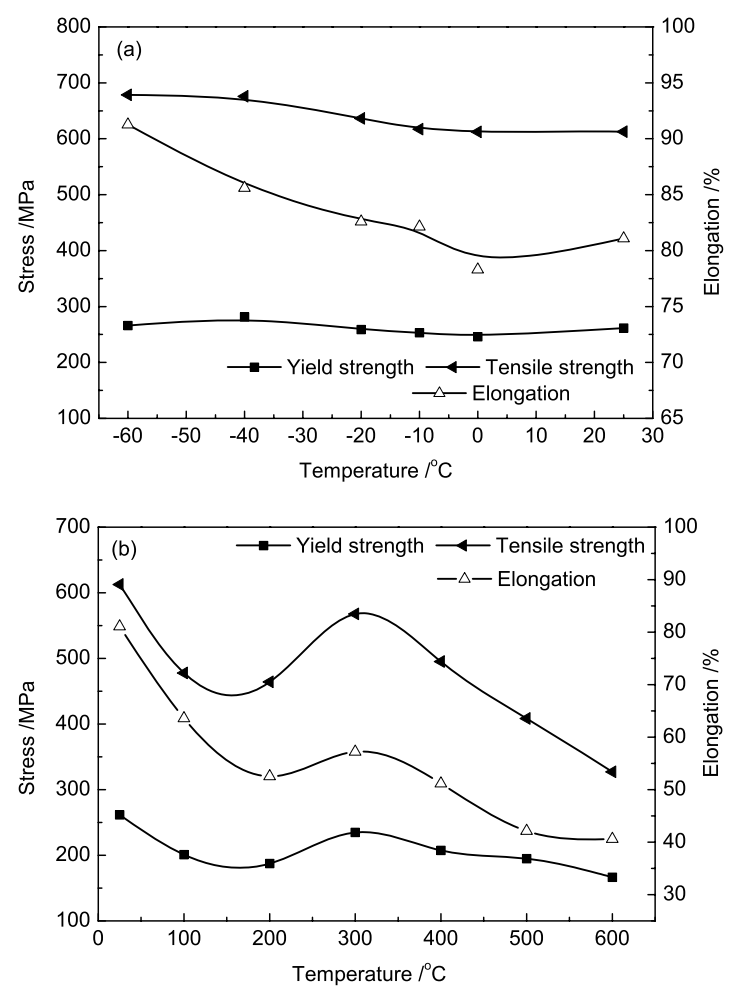

Fig. 9 Variations of the yield strength, tensile strength and elongation of Fe-23Mn-2Al-0.2C TWIP steel with lower (a) and higher (b) deformation temperatures ${ }^{[38]}$ 

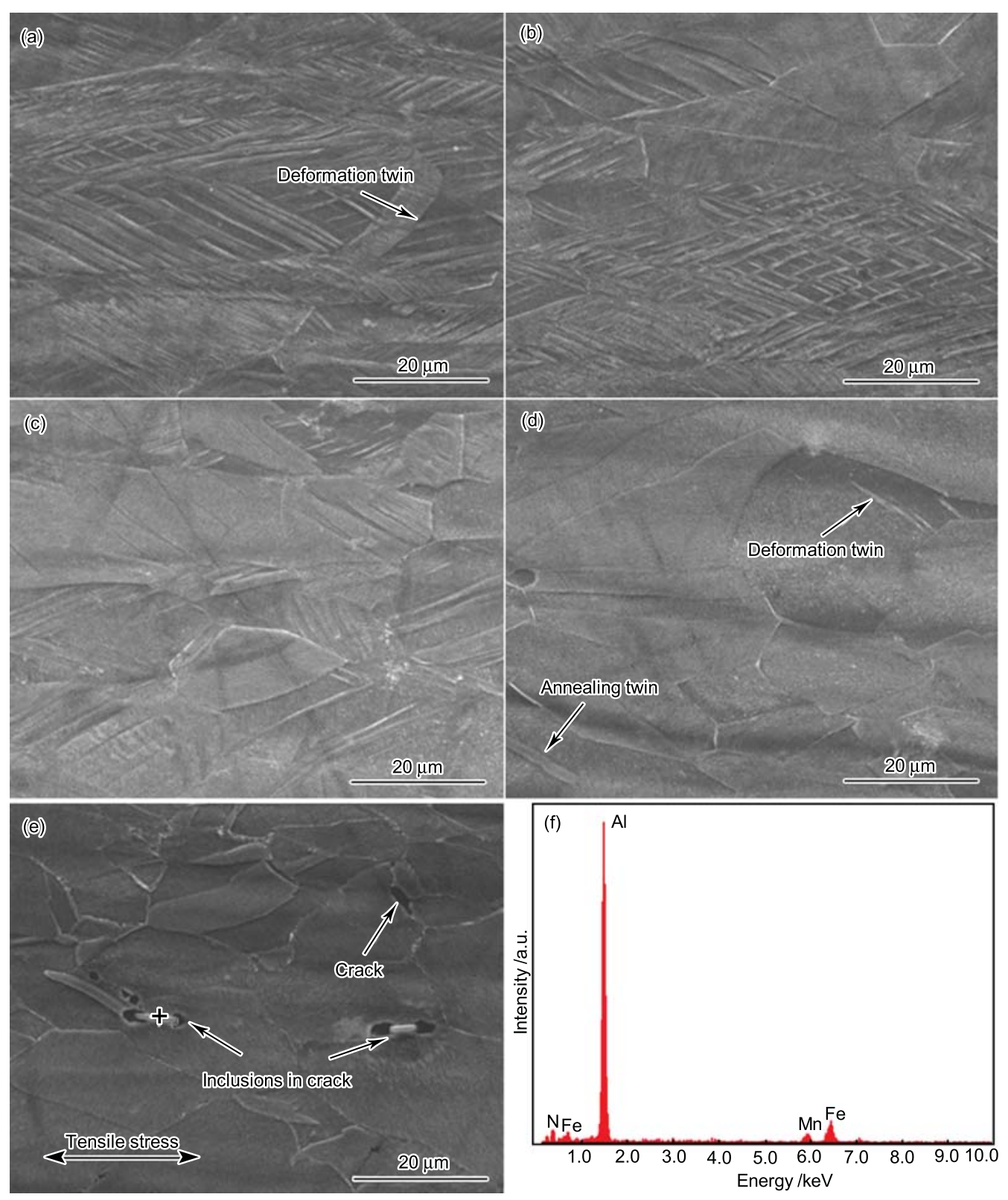

Fig. 10 SEM images showing microstructures of Fe-23Mn-2Al-0.2C TWIP steel tensile deformed at $-60{ }^{\circ} \mathrm{C}(\mathrm{a}), 25{ }^{\circ} \mathrm{C}(\mathrm{b}), 100{ }^{\circ} \mathrm{C}(\mathrm{c}), 300{ }^{\circ} \mathrm{C}(\mathrm{d}), 600{ }^{\circ} \mathrm{C}$ (e) and EDS result of the inclusion shown "+" in Fig. 10(e) (f) ${ }^{[38]}$

temperature deformation result in the high tensile strength and elongation in this steel. No deformation twins were observed when this steel was deformed at $600{ }^{\circ} \mathrm{C}$ and some micro-cracks formed at the grain boundaries, as shown in Fig. 10(e). The micro-crack always accompanied by AlN precipitates, this is due to the fact that $\mathrm{AlN}$ begin to precipitate at $600{ }^{\circ} \mathrm{C}^{[39]}$.

\subsection{Effect of strain rate on the mechanical behavior of TWIP steels}

Similar to the effect of deformation temperature, strain rate also has influence on the mechanical behavior of TWIP steels. Depending on the alloy system, the mechanical response of TWIP steel differs in the strength and elongation and the deformation mechanism varies corresponding to different strain rate ranges.

In a recent study by $\mathrm{Wu}$ et $a l .{ }^{[40]}$, the microstructure and mechanical properties of low carbon high manganese TRIP/TWIP steel Fe-18.1Mn-3.15Si$3.12 \mathrm{Al}-0.03 \mathrm{C}$ during tensile tests in the range of initial strain rate of $1.67 \times 10^{-4}-1 \times 10^{3} \mathrm{~s}^{-1}$ at room temperature were investigated. The results indicated that the inverse effect of the strain rate on the strength of steel was produced and the strength and ductility of steels decreased with increasing strain rate in the range of quasi-static tensile strain rate of the $1.67 \times 10^{-4}$ $1.67 \times 10^{-1} \mathrm{~s}^{-1}$. While inverse effect of the strain rate on ductility of the steels was produced in the range of dynamic tensile strain rate of $10-1000 \mathrm{~s}^{-1}$, the strength and ductility of the materials increased significantly with increasing strain rate. The tensile strength of high manganese TRIP / TWIP steels was 
$957 \mathrm{MPa}$ and their elongation was $55.8 \%$. These results revealed that Fe-18Mn steel had excellent mechanical properties and good fracture resistance. The higher the strain rates applied, the less martensite, the more directions of deformation twins. Martensitic transformation and deformation twins were produced during tensile deformation, and adiabatic temperature rise effect made the matrix softening during the high-rate deformation. Table 5 lists the results of mechanical properties at different strain rates for this steel.

For a solid-solution treated Fe-23Mn-2Al-0.2C TWIP steel, Qin et al. ${ }^{[41]}$ investigated the effect of strain rate on the mechanical properties. The results in Fig. 12 show that the strain rate in the range of $2.97 \times 10^{-4}-1.49 \times 10^{-1} \mathrm{~s}^{-1}$ has no obvious influence on yield strength. However, tensile strength was slightly decreased and elongation evidently decreased as the strain rate was increased. As illustrated in Fig. 13, deformation behavior with three stages was
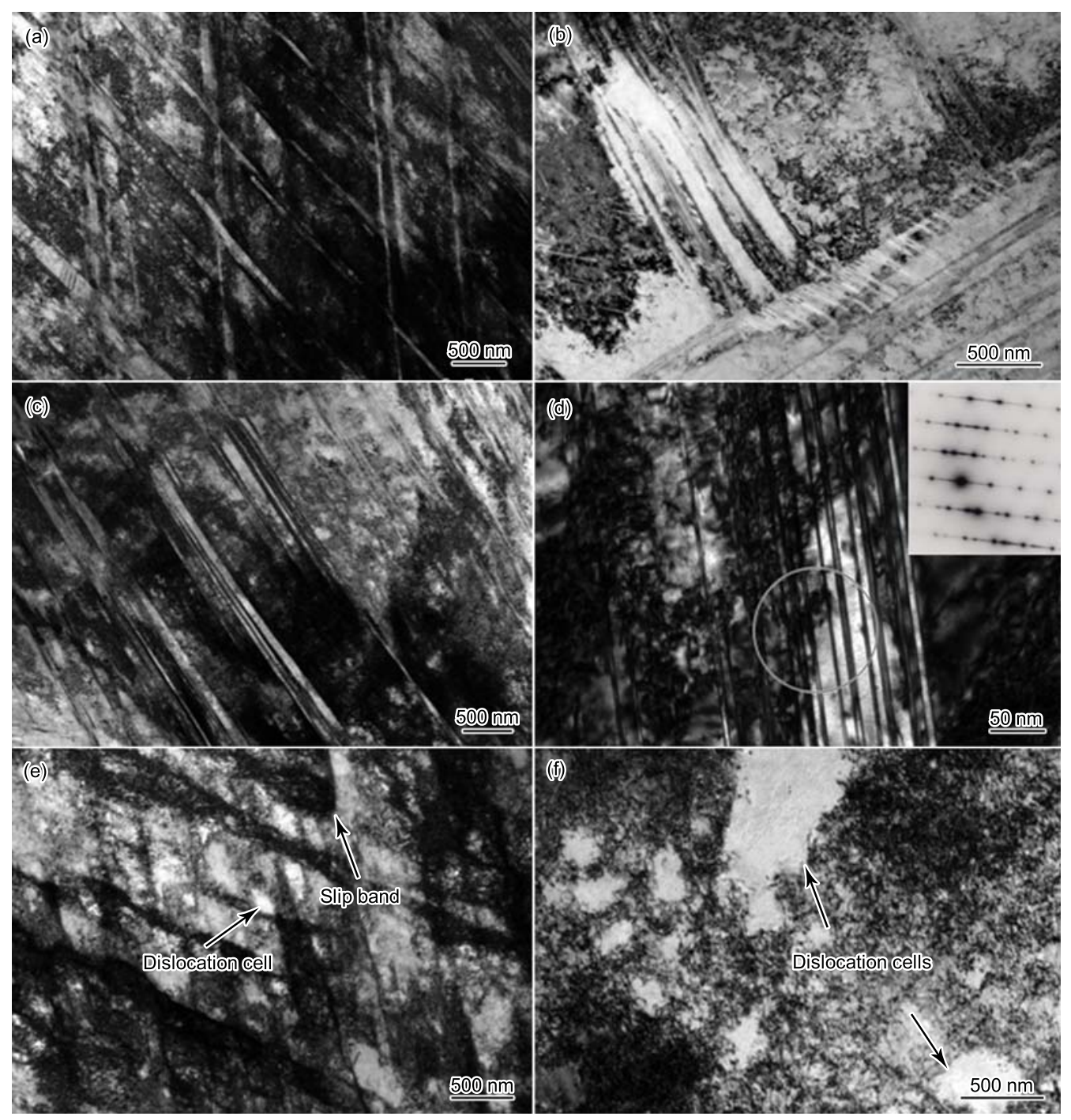

Fig. 11 TEM images of Fe-23Mn-2Al-0.2C TWIP steel tensile deformed at $-60{ }^{\circ} \mathrm{C}(\mathrm{a}),-10^{\circ} \mathrm{C}(\mathrm{b}), 25^{\circ} \mathrm{C}$ (c), $100{ }^{\circ} \mathrm{C}(\mathrm{d}), 300{ }^{\circ} \mathrm{C}(\mathrm{e})$ and $600{ }^{\circ} \mathrm{C}(\mathrm{f})$

Table 5 Ultimate tensile strength, ultimate elongation and product of strength and ductility of Fe-18.1Mn-3.15Si-3.12Al-0.03C steel at different strain rates ${ }^{[40]}$

\begin{tabular}{cccc}
\hline Strain rate $/ \mathrm{s}^{-1}$ & UTS $/ \mathrm{MPa}$ & Elongation $/ \%$ & UTS.Elongation $/ \mathrm{MPa} \%$ \\
\hline $1.67 \times 10^{-4}$ & 915 & 55 & 50325 \\
$1.67 \times 10^{-3}$ & 895 & 55 & 49225 \\
$1.67 \times 10^{-3}$ & 855 & 45 & 38475 \\
$1.67 \times 10^{-1}$ & 835 & 45 & 37575 \\
$1.00 \times 10^{1}$ & 850 & 43 & 36550 \\
$1.00 \times 10^{2}$ & 890 & 45 & 40050 \\
$1.00 \times 10^{3}$ & 957 & 56 & 53592 \\
\hline
\end{tabular}




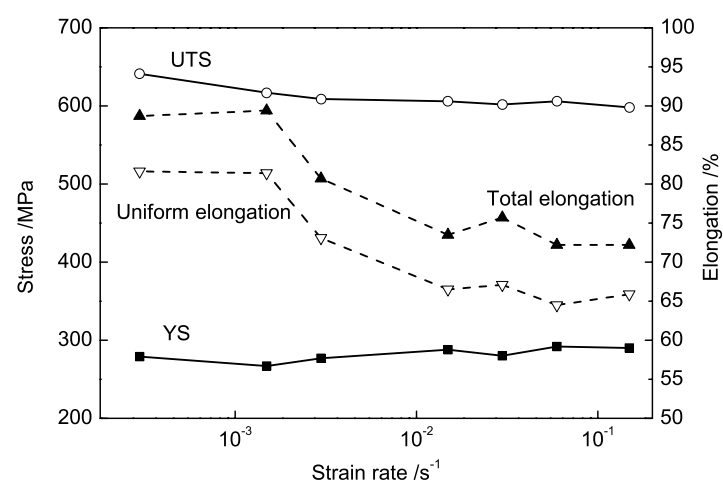

Fig. 12 Mechanical properties of the Fe-23Mn-2Al-0.2C TWIP steel deformed at different strain rates ${ }^{[41]}$
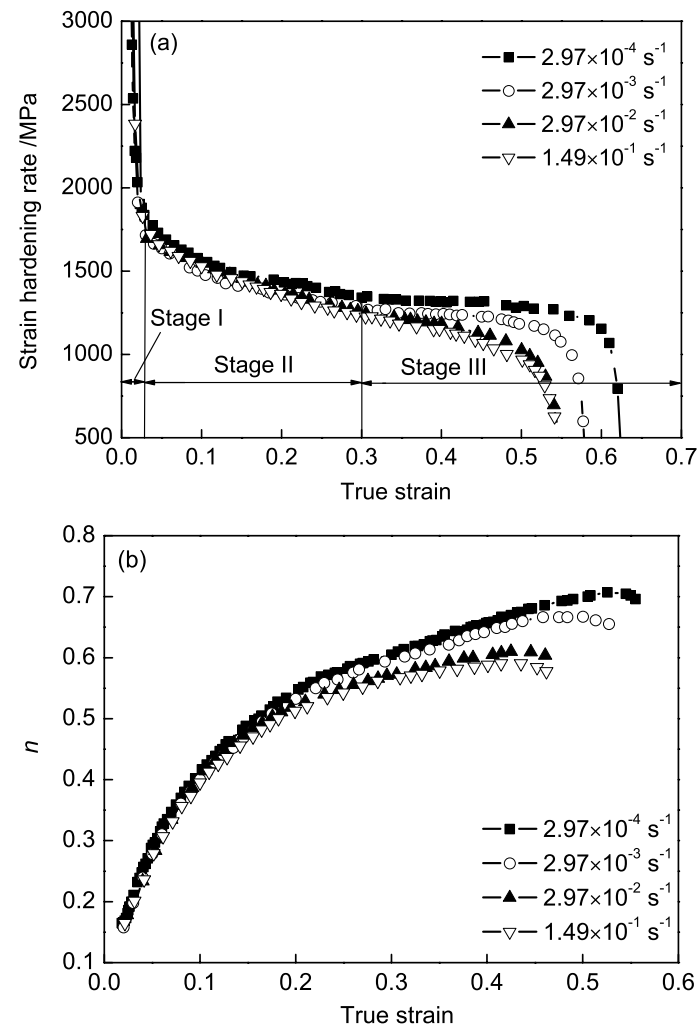

Fig. 13 Curves of the strain hardening rate $(n)$ (a) and the strain hardening exponent (b) vs. true strain for Fe-23Mn-2Al-0.2C steel at different strain rates ${ }^{[41]}$

observed as the change of strain hardening rate for low strain rate. While for high strain rate, there exist only two stages in the deformation behavior with respect to the strain hardening rate and true strain. Strain hardening exponent of this steel increases with increasing true strain. TEM micrographs in Fig. 14 revealed that high density deformation twins forms during the deformation for different strain rate, and the width of deformation twin lath decreases as the strain rate increases.

\section{Stacking Fault Energy in TWIP Steels}

The SFE is a key factor that controls the mechanical properties of the high Mn alloys and it plays an essential role in the occurrence of the TWIP effect. Some reports showed that the SFE required for the TWIP effect is $20-50 \mathrm{~mJ} / \mathrm{m}^{2}$. It is still unclear why this minimum value is essential for occurrence of the strain induced twinning, but it appears to be related to the suppression of the athermal $\gamma \rightarrow \varepsilon$ martensitic transformation ${ }^{[20]}$. In fact, in high Mn TRIP/TWIP steels the thermally induced martensites and the grain orientation will have an influence on the subsequent TRIP/TWIP process and make the microstructural evolution complicated ${ }^{[42]}$. As the SFE is an essential parameter, there has been a considerable interest in determining its value for TWIP steels.

Most authors have chosen an indirect approach trying to correlate calculations of SFE $(\Gamma)$ on a thermodynamic basis with direct observations of deformation mechanisms by $\mathrm{TEM}^{[43]}$. These calculations are based on a relationship that exists between the SFE and the driving force for $\varepsilon$-martensite formation first established by Hirth ${ }^{[4]}$ and lately popularized by Olson and Cohen ${ }^{[45]}$. The approach considers that an intrinsic stacking fault is in fact equivalent to a platelet of $\varepsilon$-martensite of a thickness of only two atomic layers creating two new $\gamma / \varepsilon$ interfaces. It follows that:

$$
\Gamma=2 \rho \Delta G^{\gamma \rightarrow \varepsilon}+2 \sigma^{\gamma / \varepsilon}
$$

where, $\rho$ is the molar surface density along $\{111\}$ planes, $\Delta G^{\gamma \rightarrow \varepsilon}$ the molar Gibbs energy of the transformation $\gamma \rightarrow \varepsilon$ and $\sigma^{\gamma / \varepsilon}$ the surface energy of the interface $\gamma \rightarrow \varepsilon$. The last term is generally taken between 5 and $15 \mathrm{~mJ} / \mathrm{m}^{2}$. The molar surface density is geometrically determined by introducing the lattice parameter $a$ of the alloy:

$$
\rho=\frac{4}{\sqrt{3}} \frac{1}{a^{2} N}
$$

where, $N$ is the Avogadro number. The estimation of the Gibbs energy $\Delta G^{\gamma \rightarrow \varepsilon}$ for the bulk $\gamma \rightarrow \varepsilon$ transformation remains the key issue ${ }^{[43]}$, and the recommended calculation of $\Delta G^{\gamma \rightarrow \varepsilon}$ may be referred to Ref. [36].

The stable and fully austenitic microstructures with TWIP properties have been reported to have the SFE in the range of 20 to $30 \mathrm{~mJ} / \mathrm{m}^{2}$ or more $^{[2,36,46-48]}$. Carbon additions are required to obtain a low SFE, but the addition of carbon is limited by the formation of $\mathrm{M}_{3} \mathrm{C}$ carbide. Some data on the effect of the carbon content in Fe-22Mn-C alloys have been reported by Yakubtsov et al. ${ }^{[48]}$ that the $\mathrm{SFE}$ of the Fe-22Mn alloy is about $30 \mathrm{~mJ} / \mathrm{m}^{2}$. Carbon additions less than $1 \mathrm{wt} \%$ reduce the SFE to approximately $22 \mathrm{~mJ} / \mathrm{m}^{2}$. At higher carbon contents the SFE is reported to increase. The critical stacking fault region to achieve twinning-induced plasticity is still unclear and there is a slight difference depending on the alloy compositions. Frommeyer et al. ${ }^{[7]}$ indicate that the SFE larger than about $25 \mathrm{~mJ} / \mathrm{m}^{2}$ will results in the twinning effect in the stable $\gamma$ phase, 

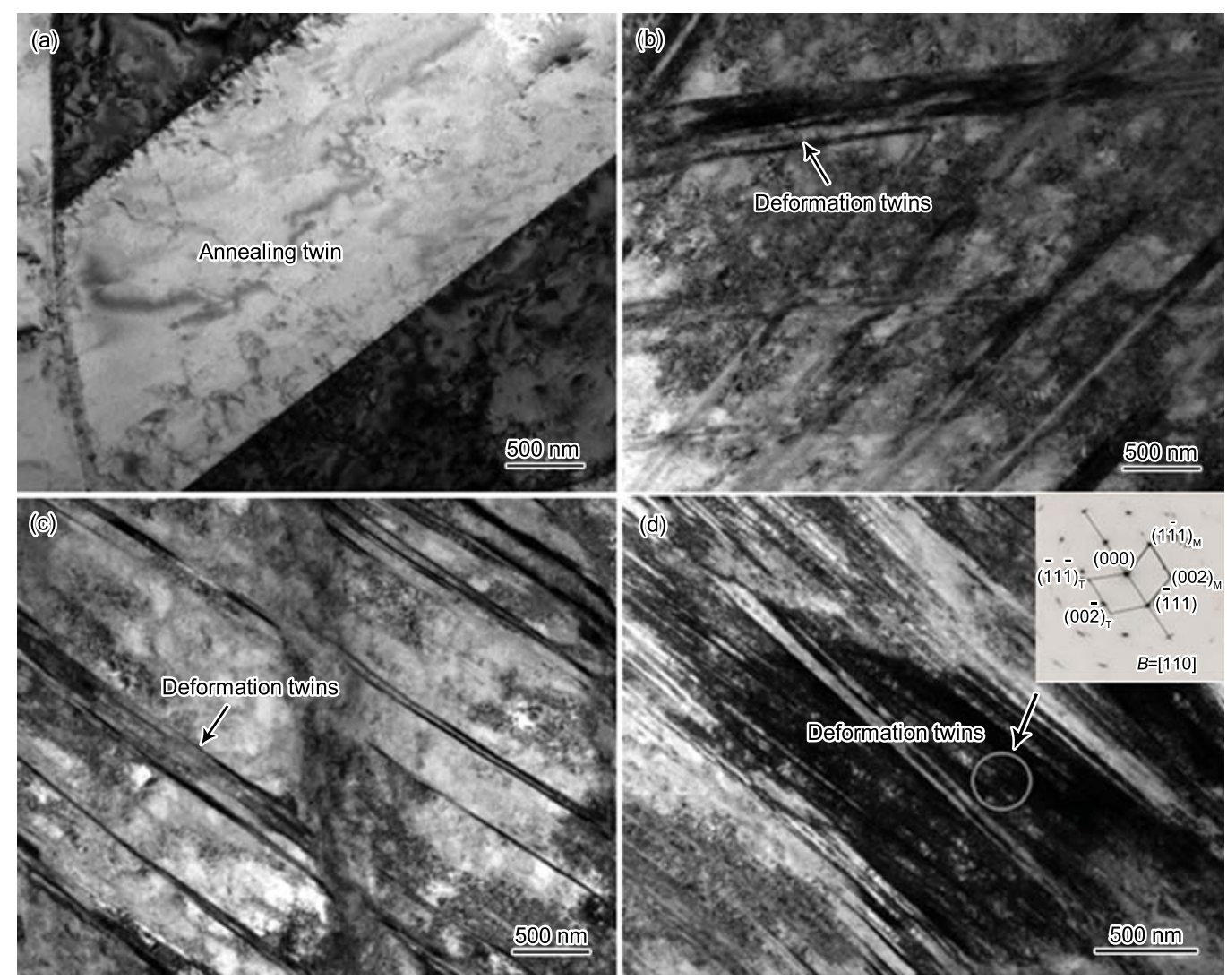

Fig. 14 TEM micrographs of Fe-23Mn-2Al-0.2C steel at different strain rates ${ }^{[41]}$ : $\dot{\varepsilon}=2.97 \times 10^{-4} \mathrm{~s}^{-1} ;(\mathrm{c}) \dot{\varepsilon}=2.97 \times 10^{-3} \mathrm{~s}^{-1} ;$ (d) $\dot{\varepsilon}=2.97 \times 10^{-2} \mathrm{~s}^{-1}$

(a) undeformed; (b)

the SFE smaller than about $16 \mathrm{~mJ} / \mathrm{m}^{2}$, results in $\varepsilon$ phase formation. Allain et al. ${ }^{[36]}$ gave a much narrower range. Dumay et al. ${ }^{[49]}$ mentioned that below the SFE of $18 \mathrm{~mJ} / \mathrm{m}^{2}$ twinning tends to disappear and is replaced by $\varepsilon$ platelets and the SFE of about $20 \mathrm{~mJ} / \mathrm{m}^{2}$ is needed for the best hardening rate. Jin et $a l .{ }^{[50]}$ suggested that the SFE value of $33 \mathrm{~mJ} / \mathrm{m}^{2}$ is required to obtain twinning in Fe-18Mn-0.6C-1.5Al. Recently, Cooman et al. ${ }^{[18]}$ measured that the SFE of Fe$18 \mathrm{Mn}-0.6 \mathrm{C}-1.5 \mathrm{Al}$ TWIP steel was $(30 \pm 10) \mathrm{mJ} / \mathrm{m}^{2}$.

Qin et al. ${ }^{[38]}$ adopted the thermodynamic approach $^{[36,44]}$ to calculate the change of SFE with deformation temperature $\left(-60-600^{\circ} \mathrm{C}\right)$ for $\mathrm{Fe}-23 \mathrm{Mn}$ $2 \mathrm{Al}-0.2 \mathrm{C}$ steel, and the dependence of SFE of the experimental steel on the temperature is shown in Fig. 15. Combing the microstructure with the SFE, they suggest that when this steel is tensile deformed at temperature of $-60-100^{\circ} \mathrm{C}$ with $\Gamma$ in the range of $14-32 \mathrm{~mJ} / \mathrm{m}^{2}$, the tensile deformed microstructures are deformation twins and deformation mechanism is twinning. Otherwise, increasing the deformation temperature will promote dislocation glide.

The same method was used by Dai et al..$^{[51]}$ to calculate the SFE of the Fe- $x \mathrm{Mn}-3 \mathrm{Si}-3 \mathrm{Al}$ system alloy and the results showed that the SFE of this alloy system increased with increasing manganese content. With the increasing of the manganese content, the Fe-

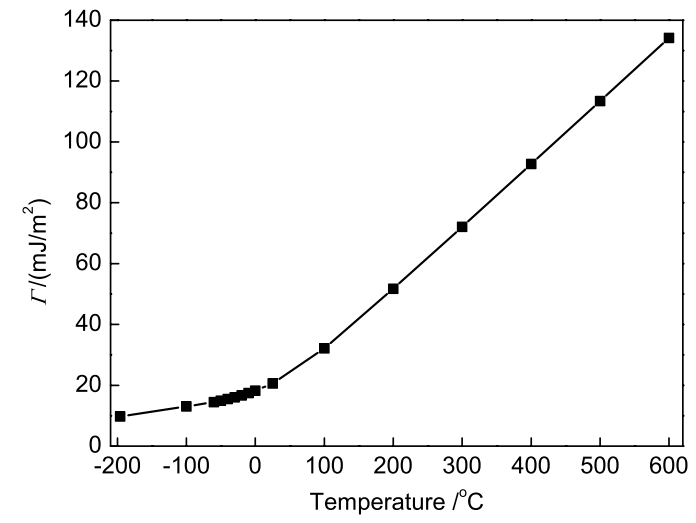

Fig. 15 Dependence of the SFE of the Fe-23Mn-2Al-0.2C steel on the temperature ${ }^{[38]}$

$x \mathrm{Mn}-3 \mathrm{Si}-3 \mathrm{Al}$ alloy system shows different deformation mechanisms from the TRIP effect turns to the TWIP effect. The relationship between the SFE of Fe- $x \mathrm{Mn}-$ $3 \mathrm{Si}-3 \mathrm{Al}$ alloy system and $\mathrm{Mn}$ content can be represented as the form:

$$
\Gamma=2.619-0.1484 x+0.053 x^{2}
$$

By using thermodynamic calculations and X-ray diffraction (XRD), Lu et al. ${ }^{[52]}$ studied the SFE of Fe$18 \mathrm{Mn}-\mathrm{Si}$ TWIP steel and the results show that the mi- 
crostructure of Fe-18Mn-Si TWIP steel after quenching is austenite. Mechanical twins and $\alpha$-martensites are observed after tensile deformation. The values of stacking fault probability and SFE are $2.6 \times 10^{-3}$ and $17.3 \mathrm{~mJ} / \mathrm{m}^{2}$, respectively. Both TWIP and TRIP effects are predicted to occur after deformation according to the calculated value of the stacking fault energy. Experimental results are consistent with the prediction. Relation between the stacking fault probability and stacking fault energy can be formulated as $\Gamma=4.498 \times 10^{-2} / P_{\text {sf }}$ for the Fe- $18 \mathrm{Mn}-\mathrm{Si}$ TWIP steel at room temperature.

An alternative approach, embedded-atom method (EAM), calculating SFE of Fe-Mn alloys was introduced by Rong et al. ${ }^{[53]}$. The calculated results based on Johnson's truncation model and its modified model indicate that the SFE in Fe-20Mn alloy increases with the increase of $\mathrm{Mn}$ content and the tendency is well consistent with their experiments. Moreover, the SFE in Fe-20Mn alloy is well agreement with the thermodynamically calculated one. The SFE of $\gamma$ phase at room temperature in Fe- $x \mathrm{Mn}$ alloys with $x=20-55$ can be expressed as $\Gamma=23.3+0.269 x$.

\section{Oxidation Resistance and Anti-corrosion Behavior of TWIP Steels}

\subsection{Oxidation behaviors of TWIP steels at elevated temperatures}

It is known that the high-temperature oxidation phenomena of the steels play an important role in formation of the surface defects in hot-rolled strip. Especially, grain-boundary oxidation in reheating furnaces causes surface defects on hot-rolled strip such as microscabs and slivers. To eliminate these defects, surface grinding of the hot-rolled strip should be performed, and this will increase the manufacturing $\operatorname{cost}^{[54]}$. Among several types of TWIP steels, much attention has been given to Fe-Mn-Al-C alloys, because of their potential for replacing $\mathrm{Ni}-\mathrm{Cr}$ stainless, cryogenic, and nonmagnetic steels ${ }^{[10-12,55-58]}$. However, the high-temperature oxidation behavior of the new austenitic, high-strength manganese alloy, Fe$\mathrm{Mn}-\mathrm{Al}-\mathrm{C}$ has not been sufficiently characterized in detail to date. Most studies on the high-temperature oxidation of high-manganese steels were dedicated to the oxidation resistance properties as feasibility studies on replacing stainless steel by high-manganese steel $^{[59,60]}$.

Park et al. ${ }^{[54]}$ investigated the oxidation behavior of a Fe-15Mn-1.5Al-0.5C alloys at extremely high temperature up to $1250{ }^{\circ} \mathrm{C}$ by using XRD and electron microscopy, and found that the oxide layers could be macroscopically classified into two zones, the external and internal oxide zones. The external-oxide zone was confirmed to be in the order of $\mathrm{Mn}_{2} \mathrm{O}_{3}, \mathrm{Mn}_{3} \mathrm{O}_{4}$, $\mathrm{MnFe}_{2} \mathrm{O}_{4},(\mathrm{Mn}, \mathrm{Fe}) \mathrm{O}$ and $\mathrm{MnAl}_{2} \mathrm{O}_{4}$ phases from the outside surface to the matrix, while the internal oxides, composed of inter- and intra-granular oxides, were identified as $\mathrm{MnAl}_{2} \mathrm{O}_{4}$ formed by the selective oxidation of manganese and aluminum. On the other hand, the $\gamma$ matrix was transformed to $\alpha$ and $\varepsilon$ phases by the selective oxidation of manganese.

The oxidation behavior of the Fe-Mn-Al alloy system has been previously investigated by several researchers ${ }^{[61-66]}$ and structures of the oxidized layers have been well characterized. Jackson and Wallwork $^{[61]}$ and Tomaszewicz and Wallwork ${ }^{[62]}$ reported that the alloys with compositions within the range Fe-(5-10) Mn-(6-10) Al develop continuous protective alumina scales and are totally ferritic. They also indicated that the growth of bulky manganeserich oxides was observed to be more easily achieved in the austenite grains, since the manganese content of the austenite region was generally much higher than that of the ferrite phase in duplex alloys. Sauer et al. ${ }^{[63]}$ reported that Fe-32Mn-7.5Al-0.6C alloys containing 1-2 wt.\% Si had good oxidation resistance at $850{ }^{\circ} \mathrm{C}$, but not at $1000{ }^{\circ} \mathrm{C}$. However, no continuous and protective $\mathrm{Al}_{2} \mathrm{O}_{3}$ were observed in the alloy systems such as Fe-32Mn-Al, Fe-35Mn-8Al and Fe-30Mn10Al-1.2Cu-1C. Erhart et al. ${ }^{[64]}$ indicated that the oxidation of Fe-30Mn-10Al-1Si specimens in $10.13 \mathrm{~Pa}$ $\mathrm{O}_{2}$ leads immediately to formation of the oxide nodules. They also reported that oxidation studies of the same material and surface preparation in air at 800, 900, 1000 and $1100{ }^{\circ} \mathrm{C}$ showed the formation of a dense, protective $\mathrm{Al}_{2} \mathrm{O}_{3}$ scale. Obviously, the high partial pressure of oxygen supports the development of a protective alumina scale which in turn gives a excellent high-temperature oxidation resistance.

In order to understand oxidation mechanism of the Fe-Mn-Al-C alloys, an investigation of the oxidation of a simple alloy belonging to the ternary Fe-Al-C alloys was made by Kao and Wan ${ }^{[65]}$, which indicated that the oxidation kinetics of Fe-5.5Al-0.55C alloy after $24 \mathrm{~h}$ oxidation at 600,800 and $1000{ }^{\circ} \mathrm{C}$ had simple, three- and two-stage parabolic rate laws, respectively. No carbide-free layer could be observed in the alloy which was oxidized at $600{ }^{\circ} \mathrm{C}$. In contrast, a carbidefree zone was found in the specimens after oxidizing at 800 and $1000{ }^{\circ} \mathrm{C}$. The differences in oxidation behavior are controlled by the stability of the carbide at different oxidation temperatures. They also reported that the oxidation behavior of Fe-7.5Al-0.65C alloy oxidized at 600 to $900{ }^{\circ} \mathrm{C}$ for $24 \mathrm{~h}$ could be classified into two groups ${ }^{[66]}$. The change in the oxidation behavior observed between 600 and 700 to $900{ }^{\circ} \mathrm{C}$ is related to the effect of the temperature on the diffusion of aluminum in the alloy. Internal oxidation occurred beneath the nodules formed on Fe-7.5Al-0.65C alloy after oxidation at $600{ }^{\circ} \mathrm{C}$, but no internal oxidation could be observed in the specimens of this alloy after $24 \mathrm{~h}$ oxidation at 700,800 and $900{ }^{\circ} \mathrm{C}$.

Recently, Qin ${ }^{[22]}$ performed an investigation of the isothermal oxidation behavior in air for Fe23Mn-2Al-0.2C TWIP steel by measuring weight gain in a high-temperature differential thermal analyzer 
at a temperature up to $1100{ }^{\circ} \mathrm{C}$, and the oxidation mechanism at different temperatures was analyzed. Fig. 16 shows the weight gain curves of Fe-23Mn-2Al$0.2 \mathrm{C}$ steel at different temperatures and Fig. 17 illustrates the weight gain per unit area (Fig. 17(a)) and per hour (Fig. 17(b)) of Fe-23Mn-2Al-0.2C steel at different temperatures.

In Fig. 16, one can see that the at the temperature lower than $600{ }^{\circ} \mathrm{C}$ the weight gain reach a stable value after oxidation of $1 \mathrm{~h}$. The weight gain is extremely low even when the oxidation temperature is up to $800{ }^{\circ} \mathrm{C}$. However, the oxidation process is to be increased by a continuous parabolic law when the reheating temperature is higher than $900^{\circ} \mathrm{C}$. This can

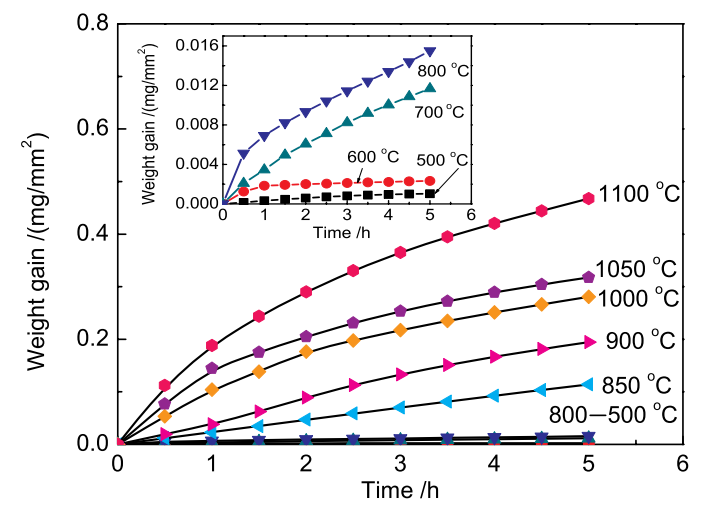

Fig. 16 Weight gain curves of Fe-23Mn-2Al-0.2C steel at different temperatures
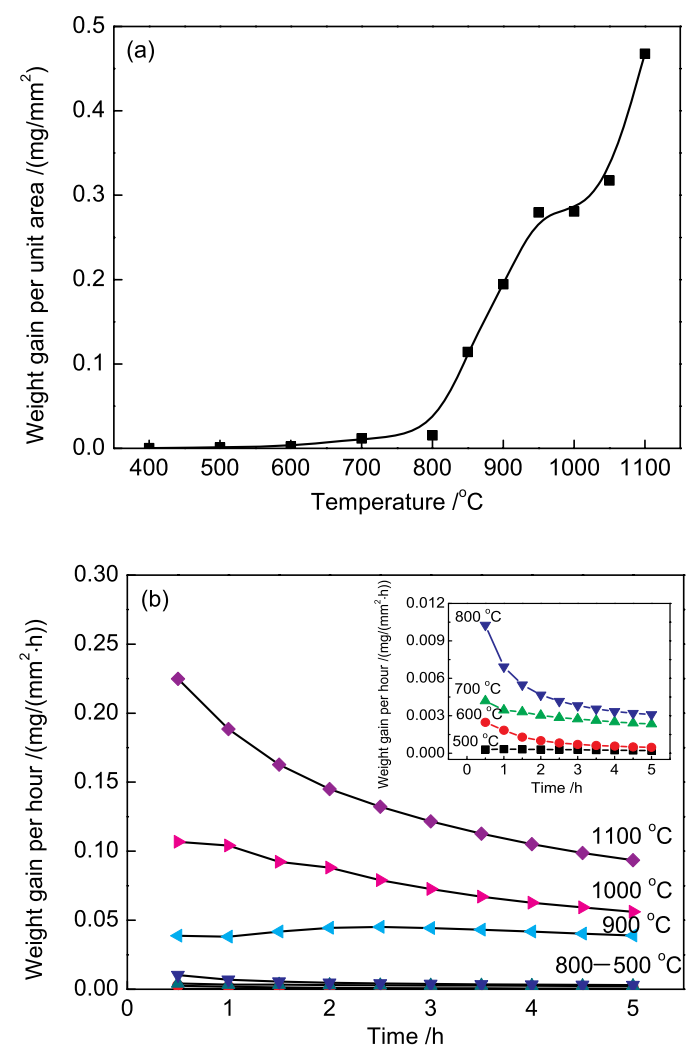

Fig. 17 Weight gain per unit area (a) and per hour (b) of Fe-23Mn-2Al-0.2C steel at different temperatures be shown clearly from the plot of weight gain per unit area vs. oxidation time at various temperatures in Fig. 17(b).

\subsection{Anti-corrosion behavior of TWIP steels}

As mentioned above, with the proper choices of chemical composition and processing, the high $\mathrm{Mn}$ austenitic Fe-Mn-Al-C system TWIP steels possess good mechanical properties, superior oxidation resistance at temperature up to 800 or $850{ }^{\circ} \mathrm{C}$, low density and low raw materials cost, and have great potential for replacing Ni-Cr austenitic stainless steel. One problem should be noticed regarding to its anticorrosion behavior at various environments, which become the most concern in engineering applications.

It has been reported that the corrosion resistance of Cr-free Fe-Mn-Al alloys is worse than that of conventional stainless steel and fully austenitic Fe-Mn-Al-based alloys have shown some promise in engineering because of their better corrosion resistance than carbon and low-alloy steels in aqueous solution ${ }^{[67]}$. One important attempt to improve the corrosion resistance of Fe-Mn-Al-C alloy is by alloying with increasing $\mathrm{Cr}$ content and lowering $\mathrm{C}$ content ${ }^{[67-70]}$, which is based on the fact that $\mathrm{Cr}$ and $\mathrm{C}$ are the ferritic and austenitic forming elements, respectively. In such a case, if Cr content is sufficiently high and $\mathrm{C}$ is too low, the microstructures will be dual-phase of the austenite and ferrite. More seriously, dual-phase Fe-Mn-Al-Cr-C alloy has poor mechanical properties as compared with austenitic alloy. Additionally, there are some problems in hot forming processes for dual-phase alloy, as demonstrated in alloys, such as Fe-(21.5-27.7)Mn-(8.9-9.9)Al-(3.1$6.2) \mathrm{Cr}-(0.33-0.42) \mathrm{C}^{[71,72]}$. Considering this, Fe-MnAl-Cr-C alloys with fully austenitic microstructure have been taken into account and the focus is put on the proper design of $\mathrm{Cr}$ and $\mathrm{C}$ contents. Alloy system Fe-(29.5-31.3)Mn-(8.4-8.9)Al-(2.6-2.8)Cr(0.98-1.06)C with low $\mathrm{Cr}$ and high $\mathrm{C}$ contents is proved to have better anti-corrosion ability than dualphase Fe-Mn-Al-Cr-C alloy or austenitic Fe-Mn-Al-C alloy ${ }^{[67,73]}$. In fact, there exist some technological difficulties in casting and welding caused by high $\mathrm{Al}$ and $\mathrm{C}$ contents, irrespective of high strength.

In a recent study, Tsay et al. ${ }^{[14]}$ reported a new high manganese austenitic Fe-28Mn-9Al-6Cr-1.8C alloy with high-strength, high-ductility and moderate corrosion resistance. This alloy contains a high density of fine ( $\mathrm{Fe}, \mathrm{Mn})_{3} \mathrm{AlC}$ carbides formed coherently within the austenite matrix during quenching. In addition, owing to the formation of the layer of $\mathrm{Cr}$ and $\mathrm{Al}$ oxides in the passive film formed on the alloys, the corrosion potential $E_{\text {corr }}(-538 \mathrm{mV})$ and the pitting potential $E_{\mathrm{p}}(-25 \mathrm{mV})$ of this alloy in $3.5 \% \mathrm{NaCl}$ solution are considerably higher than the $E_{\text {corr }}(-920-$ $-789 \mathrm{mV})$ and $E_{\mathrm{p}}(-500--240 \mathrm{mV})$ values of the asquenched and aged Fe-Mn-Al-C alloys. Whereas the 
tensile strength of this alloy is almost the same as that of conventional AISI 410 martensitic stainless steel, and it possesses superior ductility than AISI 410 martensitic stainless steel. Furthermore, in 3.5\% $\mathrm{NaCl}$ solution, the $E_{\mathrm{p}}(-25 \mathrm{mV})$ of this alloy is noticeably higher than that $(-250--100 \mathrm{mV})$ of the conventional AISI 410 martensitic stainless steel. However, this alloy is still based on the compositional design of high $\mathrm{Al}$ and $\mathrm{C}$ contents, some problems, e.g. casting and welding, remain to be examined in industrial engineering.

Undoubtedly, development of low-cost Fe-Mn-Al$\mathrm{C}$ alloy with high corrosion resistance and excellent mechanical properties is still a challenging issue and it seems that a compromise should be achieved among its alloying design, mechanical behavior, antioxidation ability and corrosion resistance in certain commercial applications.

\section{Summary}

This review introduces some fundamental aspects of TWIP steels regarding to their alloy design, correlations of mechanical behavior with the grain size, deformation temperature and strain rate, SFE and their deformation mechanisms. The oxidation behavior and corrosion resistance of TWIP steels are also addressed. Although the motive of developing TWIP steels comes from automobile manufacturing industries, from the economical view the Fe-Mn-Al-C system steels are promising in substituting stainless steels by adding appropriate content of $\mathrm{Cr}$ and/or other elements. Numerous studies have been conducted during the past several decades; however, some efforts still should be made in order to have a clear and deep understanding the relationship among their chemical compositions, microstructures and mechanical properties.

The physical metallurgy of the TWIP steels is still relatively unclear and some fundamental research works on the basis of thermodynamic calculations are required in order to have higher product of the strength and elongation with simple chemical composition system. The delicate characterization of twinning mechanism with in situ TEM and ab initio calculations of the SFE and interaction between the defects and the interstitial atoms are expected to be in progress. Determinations of the twinned volume fraction and model evaluation of the mechanical properties in associating with distribution of texture components remain open. A focus should be technologically concentrated on the Cr-containing alloy design suitable for industrialization with high anti-corrosion behavior, excellent coating and welding ability.

\section{Acknowledgement}

This work was supported by the Fundamental Research Funds for the Central Universities (No. N100507003).

\section{REFERENCES}

[1] R.A. Hadfield, Science 12 (1888) 284.

[2] V.H. Schumann, Neue Hütte 17 (1972) 605.

[3] L. Remy and A. Pineau, Mater. Sci. Eng. 28 (1977) 99.

[4] T.W. Kim and Y.G. Kim, Mater. Sci. Eng. A 160 (1993) 13.

[5] O. Grässel, G. Frommeyer, C. Derder and H. Hofman, J. Phys. IV 60 (1997) 383.

[6] O. Grässel, L. Krüger, G. Frommeyer and L. Meyer, Int. J. Plast. 16 (2000) 1391.

[7] G. Frommeyer, U. Brüx and P. Neumann, ISIJ Int. 43 (2003) 438.

[8] J.D. Yoo, S.W. Hwang and K.T. Park, Mater. Sci. Eng. A 508 (2009) 234.

[9] G. Kim, S.K. Kim, S.C. Kang and I.R. Sohn, CAMPISIJ 21 (2008) 593.

[10] J.L. Ham and R.E. Cairns, Prod. Eng. 29 (12) (1958) 50.

[11] Y.S. Chang and C.H. Shih, Acta Metall. Sin. 7 (1964) 285. (in Chinese)

[12] Y.S. Chang, C.H. Shih and Y.K. Li, Acta Metall. Sin. 8 (1965) 346. (in Chinese)

[13] J.W. Lee, C.C. Wu and T.F. Liu, Scr. Mater. 50 (2004) 1389.

[14] G.D. Tsay, C.L. Lin, C.G. Chao and T.F. Liu, Mater. Trans. 51 (2010) 2318.

[15] T.F. Liu and C.M. Wan, Scr. Metall. 19 (1985) 805.

[16] T.F. Liu and C.M. Wan, Scr. Metall. 19 (1985) 727.

[17] T.F. Liu and C.C. Wu, Scr. Metall. 23 (1989) 1087.

[18] B.C. de Cooman, K.G. Chin and J.K. Kim, In: M. Chiaberge (Ed.), New Trends and Developments in Automotive System Engineering, InTech, 2011, pp.101-128.

[19] W.S. Yang and C.M. Wan, J. Mater. Sci. 25 (1990) 1821.

[20] B.C. De Cooman, O. Kwon and K.G. Chin, Mater. Sci. Technol. 28 (2012) 513.

[21] J.K. Jung, O.Y. Lee, Y.K. Park, D.E. Kim, K.G. Jin, S.K. Kim and K.H. Song, J. Kor. Inst. Met. Mater. 46 (2008) 627.

[22] X.M. Qin, Plastic Deformation Mechanism and Microstructure, Mechaical Properties of Fe-Mn-Al-C TWIP Steels, Ph.D. Thesis, Northeastern University, 2011. (in Chinese)

[23] R. Ueji, N. Tsuchida, D. Terada, N. Tsuji, Y. Tanaka, A. Takemura and K. Kunishige, Scr. Mater. 59 (2008) 963.

[24] N. Tsuji, Y. Saito, S.H. Lee and Y. Minamino, Adv. Eng. Mater. 5 (2003) 338.

[25] N. Tsuji, Y. Ito, Y. Saito and Y. Minamino, Scr. Mater. 47 (2002) 893.

[26] S.H. Wang, Z.Y. Liu and G.D. Wang, Acta Metall. Sin. 45 (2009) 1083. (in Chinese)

[27] E. El-Danaf, S.R. Kalidindi and R.D. Doherty, Metall. Mater. Trans. A 30 (1999) 1223.

[28] S. Asgari, J. Mater. Process. Technol. 155-156 (2004) 1905.

[29] A.A.S. Mohammed, E.A. El-Danaf and A.K.A. Radwan, Mater. Sci. Eng. A 457 (2007) 373.

[30] S. Mahajan and G.Y. Chin, Acta Metall. 21 (1973) 1353. 
[31] G. Dini, A. Najafizadeh, R. Ueji and S.M. MonirVaghefi, Mater. Des. 31 (2010) 3395.

[32] G. Dini, A. Najafizadeh, S.M. Monir-Vaghefi and R. Ueji, J. Mater. Sci Technol. 26 (2012) 181.

[33] J.D. Yoo and K.D. Park, Mater. Sci. Eng. A 496 (2008) 417.

[34] D.K. Wilsdorf, Mater. Sci. Eng. A 113 (1989)1.

[35] D.A. Hughes, Acta Metall. Mater. 41 (1993) 1421.

[36] S. Allain, J.P. Chateau, O.Bouaziz, S. Migot and N.Guelton, Mater. Sci. Eng. A 387-389 (2004) 158.

[37] S.H. Wang, Z.Y. Liu, W.N. Zhang and G.D. Wang, Acta Metall. Sin. 45 (2009) 573. (in Chinese)

[38] X.M. Qin, L.Q. Chen, H.S. Di and W. Deng, Acta Metall. Sin. 47 (2011) 1117. (in Chinese)

[39] A. Brahmi and R. Borrelly, Acta Mater. 45 (997) 1889.

[40] Z.Q. Wu, Z.Y. Tang, H.Y. Li and H.D. Zhang, Acta Metall. Sin. 48 (2012) 593. (in Chinese)

[41] X.M. Qin, L.Q. Chen, W. Deng and H. S. Di, Chin. J. Mater. Res. 25 (2011) 278. (in Chinese)

[42] F.Y. Lu, P. Yang, L. Meng, F.E. Cui and H. Ding, J. Mater. Sci. Technol. 27 ( 2011) 257.

[43] O. Bouaziz, S. Allain, C.P. Scott, P. Cugy and D. Barbier, Curr. Opin. Solid State Mater. Sci. 15 (4) (2011) 141.

[44] J.P. Hirth, Metall. Trans. A 1 (1970) 2367.

[45] G.B. Olson and M. Cohen, Metall. Trans. A 7 (1976) 1897.

[46] P.H. Adler, G.B. Olson and W.S. Owen, Metall. Trans. A 17 (1986) 1725.

[47] A.P. Miodownik and Z. Metallkunde, 89 (1998) 840.

[48] I.A. Yakubtsov, A. Airapour and D.D. Perovic, Acta Mater. 47 (1999) 1271.

[49] A.Dumay, J.P. Chateau, S. Allain, S. Migot, O. Bouaziz, Mater. Sci. Eng. A 483-484 (2008) 184.

[50] J.E. Jin and Y.K. Lee, Mater. Sci. Eng. A 527 (2009) $157 .$.

[51] Y.J. Dai, D. Tang, Z.L. Mi, H.T. Jiang and J.C. Lu, J. Mater. Eng. (7) (2009) 39. (in Chinese)

[52] H.J. Lu, N.Q. Zhu, Y.L. He and L. Li, Trans. Mater. Heat Treat. 32 (12) (2011) 155. (in Chinese)
[53] Y.H. Rong, Q.P. Meng, G. He and Z.Y. Xu, J. Shanghai Jiaotong Univ. 37 (2003) 171. (in Chinese)

[54] S.H. Park, I.S. Chung and T.W. Kim, Oxid. Met. 49 (1998) 349.

[55] A. Inoue, Y. Kojima, T. Minemura and T. Masumoto, Metall. Trans. A 12 (1981) 1245.

[56] D.J. Schmatz, Trans. Am. Soc. Met. 52 (1960) 898.

[57] Y.G. Kim, J.K. Han and E.W. Lee, Metall. Trans. A 17 (1986) 2097.

[58] J. Charles, A. Berghezan, A. Lutts and P.L. Dancoisne, Met. Prog. 119 (1981) 71.

[59] J.G. Duh, J.W. Lee and C.J. Wang, J. Mater. Sci. 23 (1988) 2649.

[60] H. Schenck, E. Schmidtman and H. Muller, Arch. Eisenhuttenw 31 (1960) 121.

[61] P.R.S. Jackson and G.R. Wallwork, Oxid. Met. 21 (3-4) (1984) 135.

[62] P. Tomaszewicz and G.R. Wallwork, Corrosion 40 (4) (1984) 152.

[63] J.P. Sauer, R.A. Rapp and J.P. Hirth, Oxid. Met. 18 (5-6) (1982) 285.

[64] H. Erhart, R. Wang and R.A. Rapp, Oxid. Met. 21 (1-2) (1984) 81.

[65] C.H. Kao and C.M. Wan, J. Mater. Sci. 22 (1987) 3203.

[66] C.H. Kao and C.M. Wan, J. Mater. Sci. 23 (1988) 1943.

[67] S.C. Chang, J.Y. Liu and H.K. Juang, Corrosion 51 (5) (1995) 399.

[68] C.J. Wang and Y.C. Chang, Mater. Chem. Phys. 76 (2002) 151.

[69] C.S. Wang, C.Y. Tsai, C.G. Chao and T.F. Liu, Mater. Trans. 48 (2007) 2973.

[70] Y.H. Tuan, C.S. Wang, C.Y. Tsai, C.G. Chao and T.F. Liu, Mater. Chem. Phys. 114 (2009) 595.

[71] S.M. Zhu, S.C. Tjong, Scr. Mater. 36 (1997) 317.

[72] S.T. Shih, C.Y. Tsai and T.P. Perng, Corrosion 49 (1) (1993) 130.

[73] S.C. Chang, W.H. Weng, H.C. Chen, S.J. Lin and P.C.K. Chung, Wear 181-183 (1995) 511. 